\title{
$\beta$-Sitosterol Contributes in the Resistance to Invasion and Survival of Brucella abortus 544 within RAW264.7 Cells, and Cytokine Production with Reduced Susceptibility to Infection in BALB/c Mice
}

\author{
Alisha Wehdnesday Bernardo Reyes ${ }^{1}$, Lauren Togonon Arayan ${ }^{1}$, Tran Xuan Ngoc Huy ${ }^{1}$, Son Hai \\ $\mathrm{Vu}^{1}$, Wongi Min ${ }^{1}$, Jin $\mathrm{Hur}^{2}$, and Suk Kim ${ }^{1 *}$ \\ 'Institute of Animal Medicine, College of Veterinary Medicine, Gyeongsang National University, Jinju 52828, \\ Republic of Korea \\ ${ }^{2}$ Veterinary Public Health, College of Veterinary Medicine, Chonbuk National University, Iksan 54596, Republic of \\ Korea \\ We previously identified $\beta$-sitosterol (BS) as one of the most abundant compounds found in Korean \\ red ginseng oil. BS is a widely prevalent vegetable-derived phytosterol with many known health \\ benefits. Here, we investigated the efficacy of BS against Brucella (B.) abortus infection. BS showed \\ no effect on bacterial growth but attenuated internalization, intracellular survival and MAPKs- \\ linked intracellular signaling in RAW264.7 cells. BS treatment in cells is also associated with \\ increased nitrite concentration during infection at $24 \mathrm{~h}$. Slightly enhanced resistance to $B$. abortus \\ infection was observed in mice orally given BS, which could be mediated by induced production of \\ proinflammatory cytokines. Taken together, our study demonstrates the contribution of BS \\ treatment against $B$. abortus infection although further investigation is encouraged to maximize its \\ beneficial effects against intracellular infection.
}

Keywords: Brucella abortus, $\beta$-sitosterol, macrophage, internalization, cytokine

Received: September 30, 2019 Accepted: December 24, 2019

First published online: December 30, 2019

*Corresponding author Phone: +82-55-772-2359 Fax: +82-55-772-2349 E-mail: kimsuk@gnu.ac.kr

pISSN 1017-7825 elSSN 1738-8872

Copyright(C) 2020 by The Korean Society for Microbiology and Biotechnology

\section{Introduction}

Brucella abortus is a highly pathogenic zoonotic agent, a common source of human infection and with 500,000 reported cases annually, brucellosis stands first in the list of zoonotic bacterial diseases $[1,2]$. Fever is one of the most common symptoms in human but the disease also increases the risk of spontaneous abortion, premature delivery, miscarriage and intrauterine infection with fetal death accompanied with malaise, fatigue and arthritis [2]. The etiologic agent has developed a stealthy strategy that allows it to circumvent strong innate immune system activation, withstand the direct action of complement and other bactericidal substances, evade the action of professional phagocytes, and maintain the host cells alive to establish long lasting infections [3]. There is no current available specific diagnostic test to identify Brucella with consistent false negativity obtained using serological tests at the early days of infection [2]. Although mortality rate is low, treatment of human brucellosis is still controversial with no prophylaxis [1]. Current standard treatment regimens for brucellosis include a combination of tetracycline, trimethoprim-sulfamethoxazole, aminoglycosides, rifampicin, quinolones, chloramphenicol, doxycycline and streptomycin but a higher incidence of failure or relapse still occurs in monotherapy [4]. Furthermore, an increasing problem of antibiotic resistance poses a serious global threat to human, animal and environmental health [5].

In a study done by Nath et al. [6], the blood biochemical metabolites of crossbred cattle suffering from brucellosis showed increased serum cholesterol level in comparison to healthy cattle, and Ali [7] documented abnormally high serum concentration of total cholesterol in brucellosis patients than in healthy control group. Lin et al. [8] reported that the role of cholesterol in pathogen-host interactions contributed to promote the survival of pathogen and its virulence delivery into host. On the other hand, $\beta$-sitosterol (BS) is a compound structurally related to cholesterol that is slowly absorbed in the intestinal tract, hence can interfere in the absorption of cholesterol and its rise in serum [9]. BS is a natural micronutrient found in numerous plants and considered as one of the most prevalent vegetable-derived phytosterols in the diet proven to be a safe, non-toxic, effective nutritional supplement with potential health benefits in many diverse applications including antibacterial and antiviral 
activities, modulation of immune function, inflammation and pain levels by controlling the production of inflammatory cytokines, and inhibitor of arthritis, ulcer and cancer $[9,10]$. Furthermore, we previously reported that BS is one of the abundant compounds identified in the phytochemical analysis of Korean red ginseng oil which could be attributed to its immunomodulatory activity [12]. Given the reported beneficial properties of BS, we investigate its effect against $B$. abortus infection using a murine macrophage cell line and a murine model in the context of phagocytosis and intracellular bacterial survival, and immune modulation and control of bacterial proliferation, respectively, for finding a viable alternative approach that is natural, safe and effective for the treatment and control of brucellosis.

\section{Materials and Methods}

\section{$\beta$-Sitosterol (BS) Preparation}

BS was purchased from Sigma Chemical Co. (molecular weight $414.71 \mathrm{~g} / \mathrm{mol}$, USA), dissolved in absolute ethanol $(100 \mathrm{mM})$ and diluted in sterile phosphate buffered saline (PBS) solution ( $\mathrm{pH} 7.4)$ containing $0.1 \%$ bovine serum albumin (BSA) (GenDEPOT, USA).

\section{Bacterial Strain and Cultivation}

The standard wild-type B. abortus 544 (ATCC 23448) was maintained in Brucella broth (Becton Dickin, USA) at $37^{\circ} \mathrm{C}$ for 2 days with vigorous shaking. Serial dilutions of a sample were plated on Brucella agar incubated at $37^{\circ} \mathrm{C}$ for 3 days to determine colony forming units (CFUs).

\section{Cell Culture and Cultivation}

The RAW264.7 macrophage cell line (ATCC TIB7-1, USA) was maintained in RPMI 1640 medium containing $10 \%$ heat-inactivated fetal bovine serum (FBS), $100 \mathrm{U} / \mathrm{ml}$ penicillin and $100 \mu \mathrm{g} / \mathrm{ml}$ streptomycin (Invitrogen, USA) in a $5 \% \mathrm{CO}_{2}$ atmosphere at $37^{\circ} \mathrm{C}$. Prior to infection, the medium was changed to fresh medium without antibiotics.

\section{Cytotoxicity Assay}

RAW264.7 cells $\left(1 \times 10^{5}\right.$ cells/well $)$ were seeded into a 96-well tissue culture plate and cultured overnight. Cells were then treated with different concentrations of BS $(0,10,20,50,100,200,500 \mu \mathrm{M})$ for $48 \mathrm{~h}$ in fresh medium. Viability of cells was assessed using MTT assay as previously described [11]. A $0.1 \%$ ethanol and $0.1 \%$ BSA in appropriate medium was used as control in all experiments. The highest non-cytotoxic concentration of BS was used in the succeeding experiments.

\section{Bactericidal Assay}

B. abortus $\left(2 \times 10^{4} \mathrm{CFU} /\right.$ well $)$ were incubated into different concentrations of BS $(0,10,50,100,500 \mu \mathrm{M})$ in a 96 well plate for 0, 2, 24, and $48 \mathrm{~h}$ in PBS. Each sample was serially diluted using PBS and plated on Brucella agar to determine the direct effect of BS on B. abortus growth. Bacterial survival rates were determined as a percentage of survival rate of BS-treated sample relative to control sample which was set to $100 \%$.

\section{Nitrite Assay}

Preparation of RAW264.7 cells was similar with cytotoxicity assay. The cells were pre-treated with BS $(20 \mu \mathrm{M})$ for $4 \mathrm{~h}$ and then washed prior to infection. B. abortus at a multiplicity of infection (MOI) of 100 were deposited onto cells, centrifuged at $150 \times g$ for $10 \mathrm{~min}$ and then incubated for $1 \mathrm{~h}$ at $37^{\circ} \mathrm{C}$ in a $5 \% \mathrm{CO}_{2}$ atmosphere. The cells were washed and incubated in fresh medium containing gentamicin $(30 \mu \mathrm{g} / \mathrm{ml})$ with or without BS $(20 \mu \mathrm{M})$ for 2,24 , and $48 \mathrm{~h}$. Nitrite accumulation was measured as an indicator of nitric oxide (NO) production based on Griess reaction (Promega Corporation, USA) according to manufacturer's instruction.

\section{Infection Assay}

To determine the efficiency of bacterial uptake, cells were prepared similar to cytotoxicity assay and then pretreated with BS $(20 \mu \mathrm{M})$ for $4 \mathrm{~h}$ prior to infection. Bacteria were deposited onto cells at MOI of 100, centrifuged for $10 \mathrm{~min}$ and then incubated for 0 and $30 \mathrm{~min}$ at $37^{\circ} \mathrm{C}$ in a $5 \% \mathrm{CO}_{2}$ atmosphere. After incubation, the cells were washed three times, incubated in fresh medium with gentamicin for $30 \mathrm{~min}$ and then lysed with distilled water. To determine the efficiency of bacterial intracellular growth, cells were prepared as that of the invasion assay but the cells were infected first for $1 \mathrm{~h}$ prior to incubation in fresh medium containing gentamicin with BS $(20 \mu \mathrm{M})$ for 2 , 24 , and $48 \mathrm{~h}$. After incubation, cells were washed and then lysed with distilled water. Each sample was serially diluted and then plated onto Brucella agar to determine the number of viable bacteria by counting CFUs as previously described [11].

\section{Immunoblot Analysis}

RAW264.7 cells $\left(1 \times 10^{6}\right.$ cells/well $)$ were seeded into a 6-well tissue culture plate and cultured overnight. Pretreatment and infection of cells were the same as in invasion assay. At $30 \mathrm{~min}$ pi, cell lysates were collected, protein concentrations were determined using Bradford protein assay and were boiled for $5 \mathrm{~min}$ in $2 \mathrm{x}$ Laemmli sample buffer (Bio-Rad Lab. Inc., USA). Immunoblot assay was performed with slight modifications as we previously described [11]. Briefly, membranes were incubated with phospo-specific antibodies against ERK, JNK and p38 $\alpha$ (1:250, Cell Signaling Technology, Inc., USA) in 5\% bovine serum albumin (GenDEPOT, USA) at $4^{\circ} \mathrm{C}$ overnight. Incubation with secondary antibody was done using peroxidase-conjugated anti-rabbit IgG (Thermo Scientific, 
USA; 1:1,000 dilution) at room temperature for $1 \mathrm{~h}$. $\beta$-actin antibody was used as a loading control. Membranes were exposed to a Molecular Imager ChemiDoc XRS+ system machine (Bio-Rad Lab.). NHI ImageJ software (USA) was used to quantify the immunoblots.

\section{In vivo Experiment}

Eight-week old pathogen-free female BALB/c mice (Samtako Bio Co. Ltd., Korea) were acclimatized for one week and assigned randomly into four groups of five mice each. The animals were orally given with $100 \mu \mathrm{l}$ of BS $(20 \mu \mathrm{M})$ or vehicle ( $0.1 \%$ ethanol and $0.1 \%$ BSA in PBS) using a gavage needle for three days prior to infection until 14 days post-infection (pi). The groups were subdivided into infected and non-infected groups. The infected groups were intraperitoneally infected with $B$. abortus $\left(2 \times 10^{4} \mathrm{CFU}\right.$ in $\left.100 \mu \mathrm{lPBS}\right)$ and the blood was collected via tail vein at 3 days post-infection (pi). The mice were sacrificed, blood was collected from the heart and the spleens were collected and weighed. A part of each spleen was homogenized and serially diluted in PBS. The samples were then plated onto Brucella agar and incubated at $37^{\circ} \mathrm{C}$ for 3 days to determine the number of CFUs in each spleen. The aforementioned procedures were in compliance with established federal guidelines and institutional policies by the Animal Ethical Committee of Chonbuk National University (Authorization Number CBNU-2019-53).

\section{Cytometric Bead Array (CBA)}

Serum samples were collected and processed to measure the level of different cytokines involved in the outcome of Brucella infection such as IL-12p70, TNF, IFN- $\gamma$, MCP-1, IL-10, and IL-6 using a Cytometric Bead Array (CBA) mouse inflammation kit (BD Biosciences, USA) according to manufacturer's instruction. The samples were acquired on a FACSCalibur flow cytometer (BD Biosciences) and analyzed using BD CellQuest software.

\section{Enzyme-Linked Immunosorbent Assay (ELISA)}

Serum alanine aminotransferase 1 (ALT) concentration was determined using an ALT (Mouse) ELISA kit (BioVision Inc., USA) to determine liver damage or injury during the course of BS treatment while IL- $1 \beta$ was measured using IL-1 beta Mouse SimpleStep ELISA kit (Abcam, USA) according to manufacturer's instructions.

\section{Statistical Analysis}

The data are expressed as the mean \pm standard deviation (SD) and comparisons between groups were analyzed using Student's $t$-test. $p<0.05$ was considered as statistically significant.

\section{Results}

Effect of BS on RAW264.7 Cell Viability, B. abortus Growth and Nitrite Production

In the cytotoxicity assay, a reduced OD value was observed at concentrations $50,100,200$, and $500 \mu \mathrm{M}$. The highest non-cytotoxic concentration of BS $(20 \mu \mathrm{M})$ in which the viability of RAW264.7 cells remained 100\% was used in the succeeding experiments (Fig. 1A). Bacterial survival rates were not affected at any concentrations of BS used in the experiment (Fig. 1B). On the other hand, nitrite accumulation at all time points $(2,24$, and $48 \mathrm{~h}$ ) was not affected in treatment cells without B. abortus infection (data not shown) but markedly increased in Brucellainfected BS-treated cells at $24 \mathrm{~h}(p<0.05)$ pi in comparison with the control (Fig. 1C). NO is known to be an important effector molecule involved in the clearance of several intracellular bacteria including B. abortus [12]. Taken together, BS treatment did not directly affect the growth of $B$. abortus but slightly enhanced the production of nitrite during Brucella infection in macrophages.

Effect of BS in Brucella Uptake and Intracellular Survival Within RAW264.7 Cells

Treatment of macrophages with BS markedly reduced the uptake of B. abortus into these cells at $30 \mathrm{~min}(p<0.01)$ pi (Fig. 2A) and the bacterial intracellular survival at $48 \mathrm{~h}(p<0.01)$ pi (Fig. 2B). Furthermore, we checked the phosphorylation level of mitogen-activated protein kinases (MAPKs) which are known to coordinately regulate gene expression, mitosis, metabolism, motility, survival, apoptosis and differentiation [13]. MAPKs also play an important role in the phagocytosis of bacteria hence a common target for obligate intracellular parasites for invasion. Phosphorylation of JNK was reduced $(p<0.01)$ in BS-treated cells while no differences were observed in the phosphorylation levels of ERK and p38 $\alpha$ (Fig. 3). The inhibitory effect of BS on MAPKs could negatively affect the ability of $B$. abortus to invade and survive within macrophages.

\section{Effect of BS in Mice and Against B. abortus Infection}

No clinical symptoms during the entire treatment period were observed in all the animals. In the non-infected groups, we checked the effect of BS treatment in the total body weight and the serum ALT concentration. The results showed no differences in the total body weight (Fig. 4A) and serum ALT concentration (Fig. 4B), as well as in the splenic weight (Fig. 5A). On the other hand, since spleen is one of the most notable infected organs during $B$. abortus infection in mice with the higher number of CFU per gram of organ generally reaching its maximum $\mathrm{CFU}$ at two weeks pi [14], we checked the proliferation of B. abortus in these organs. First, no difference in the total weights of the spleens was observed between BS-treated $(0.130 \pm 0.017 \mathrm{~g})$ and vehicle-treated mice $(0.133 \pm$ $0.021 \mathrm{~g})$ (Fig. 5A), however a slight significant reduction $(0.517 ; p<0.01)$ in the number of $\log _{10} \mathrm{CFU}$ was observed in mice treated with BS as compared to positive control group (Fig. 5B).

Effect of BS on Cytokine Production In Mice

Serum samples collected at 3 and 14 days pi from all mice were evaluated for the potential immunoregulatory role 

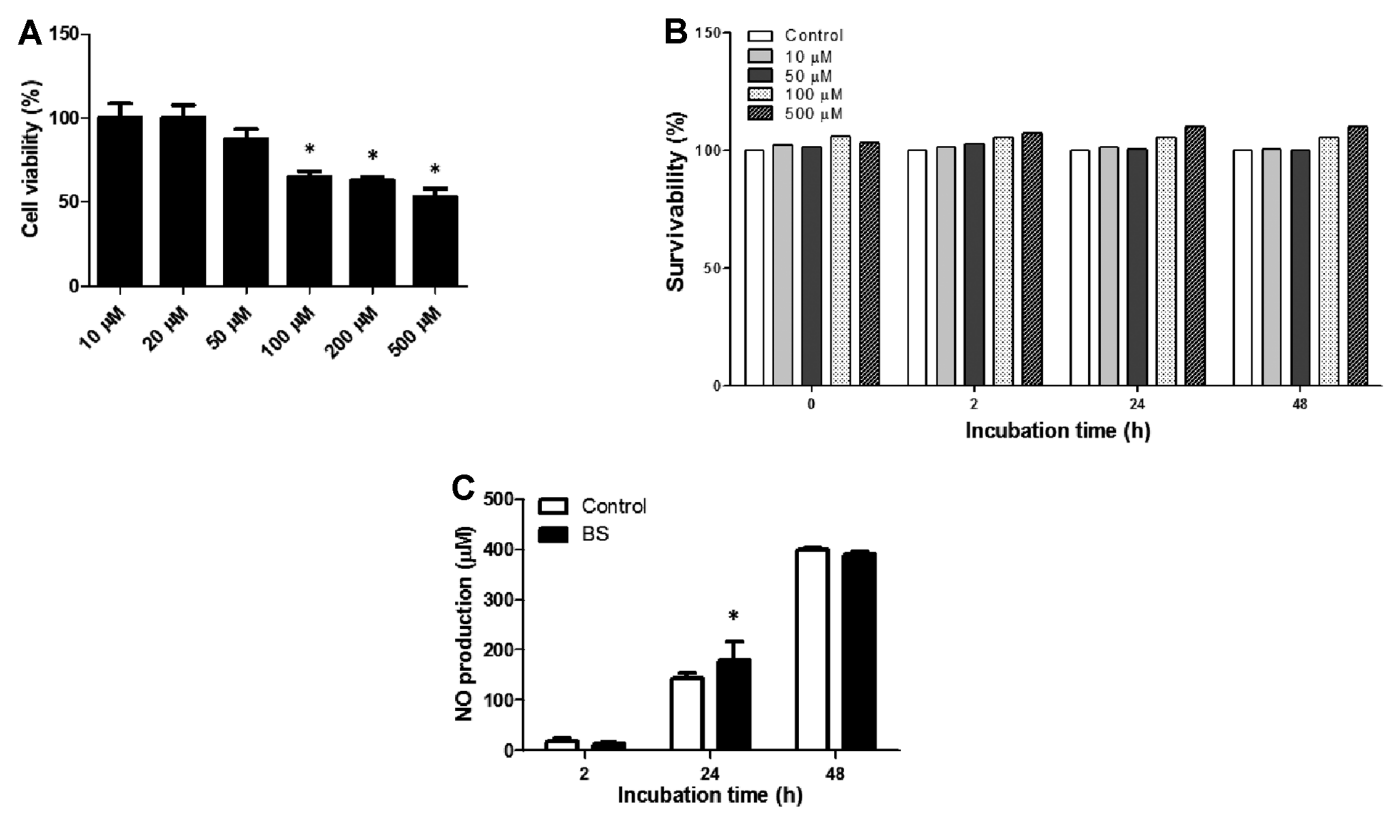

Fig. 1. Effect of BS on cell viability, bacterial survivability and nitrite production. RAW264.7 cells were incubated with different concentrations of BS for $48 \mathrm{~h}$ and (A) cell viability was evaluated using MTT assay. B. abortus was incubated with different concentrations of BS for $0,2,24$, and $48 \mathrm{~h}$, and (B) bacterial survival rates were determined. Cells were pre-incubated with or without BS and then infected with $B$. abortus for $1 \mathrm{~h}$, and (C) nitrite accumulation was measured after 2, 24, and $48 \mathrm{~h}$ by Griess reaction. The data are presented as the means $\pm \mathrm{SD}$ of triplicate experiments. ${ }^{\star} p<0.05 v s$. control group.
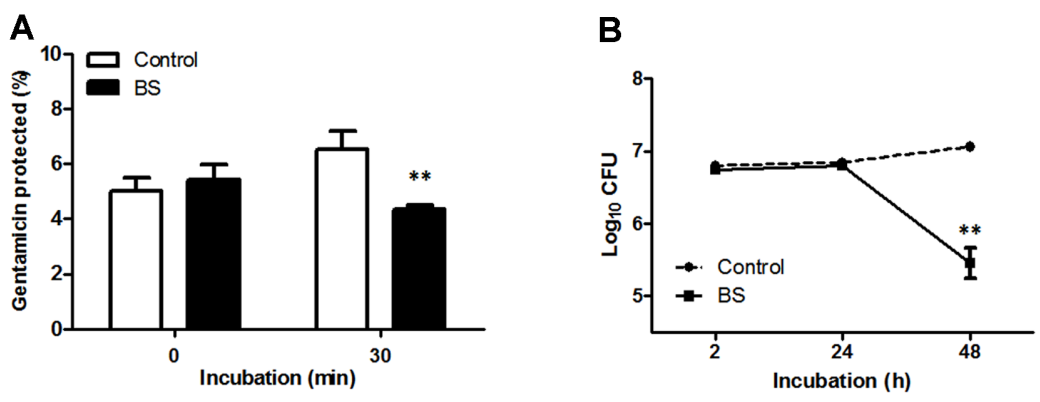

Fig. 2. Effect of BS on internalization and intracellular survival of B. abortus in RAW264.7 cells. Cells were preincubated with or without $\mathrm{BS}$ for $4 \mathrm{~h}$ prior to infection with $B$. abortus for 0 and $30 \mathrm{~min}$ to determine (A) bacterial internalization efficiency. After $1 \mathrm{~h}$ infection with B. abortus, cells were incubated with or without BS for 2, 24, and $48 \mathrm{~h}$ to determine (B) bacterial intracellular survival efficiency. The data are presented as the means $\pm \mathrm{SD}$ of triplicate experiments. ${ }^{*} p<0.01 v s$. control group.

of BS with or without B. abortus infection. In the Brucella-infected groups, significant increased levels of IL-12p70 $(p<0.001)$, TNF $(p<0.05)$ and IL-6 $(p<0.05)$ were observed at 3 days pi (Fig. 6A) while elevated levels of IL-12p70 $(p<0.05)$, TNF $(p<0.01)$, IFN- $\gamma(p<0.01)$, MCP-1 $(p<0.05)$ and IL-1 $\beta(p<0.05)$ were observed at 14 days pi (Fig. 6B) in BS-treated mice as compared to control. Furthermore, reduced level of IL-10 $(p<0.05)$ was observed at 14 days pi (Fig. 6B). These findings indicate that BS treatment in mice could induce production of proinflammatory cytokines during B. abortus infection.

\section{Discussion}

Brucellosis is one of the most widespread zoonotic diseases with a high morbidity in developing countries and yet still with undetermined optimal treatment [4]. Macrophages/monocytes are the primary target cells and a main reservoir of Brucella that constitute the first line of defense dedicated to eliminate invading microorganisms and display a wide array of phagocytic and inducible microbicidal functions such as the production of reactive oxygen and nitrogen intermediates through oxidative bursts [15]. However, Brucella use several strategies to survive within a hostile environment and cause persistent infection that are essential for the dissemination of the pathogens within the host [16]. After phagocytosis, it has been reported that over $90 \%$ of internalized Brucella in macrophages are killed but few still escape to establish an intracellular niche without affecting the survival of these 

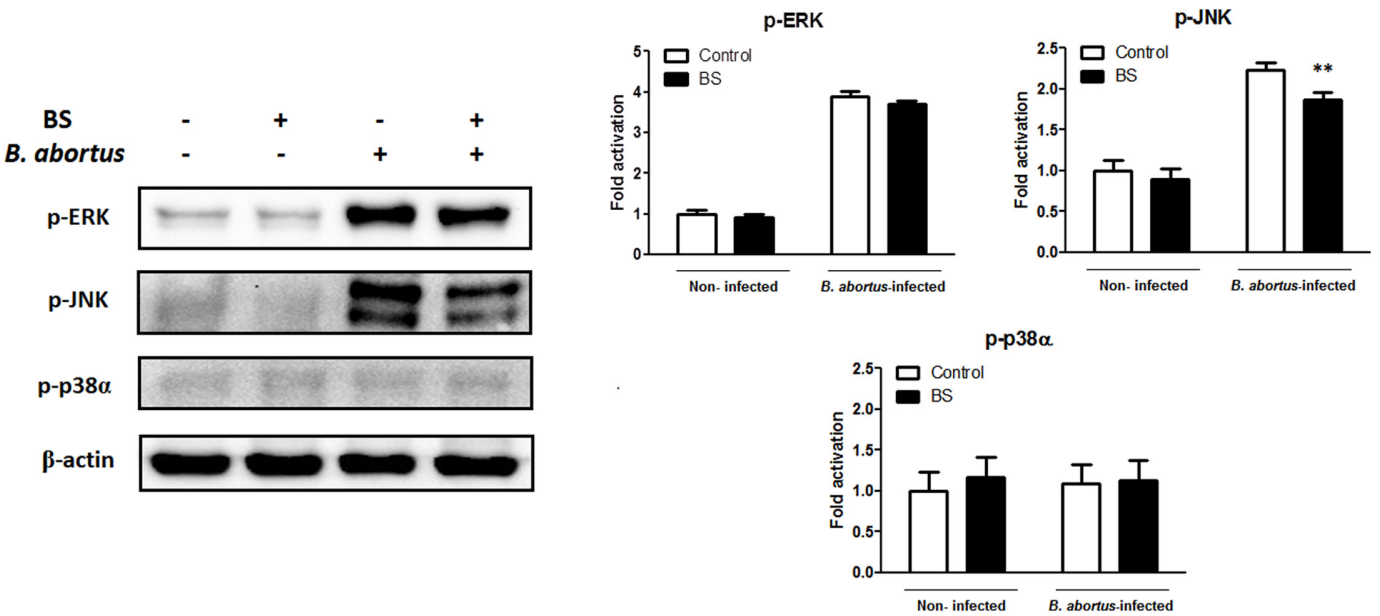

Fig. 3. Effect of BS on MAPKs activation in RAW264.7 cells. Cells were pre-incubated with or without BS for $4 \mathrm{~h}$ prior to infection with $B$. abortus for $30 \mathrm{~min}$. Immunoblot analysis of total cell lysates was assessed using phospho-specific ERK1/2, JNK and $\mathrm{p} 38 \alpha$ antibodies. The data are presented as the means \pm SD of triplicate experiments. ${ }^{* *} p<0.01 v$ s. control group.
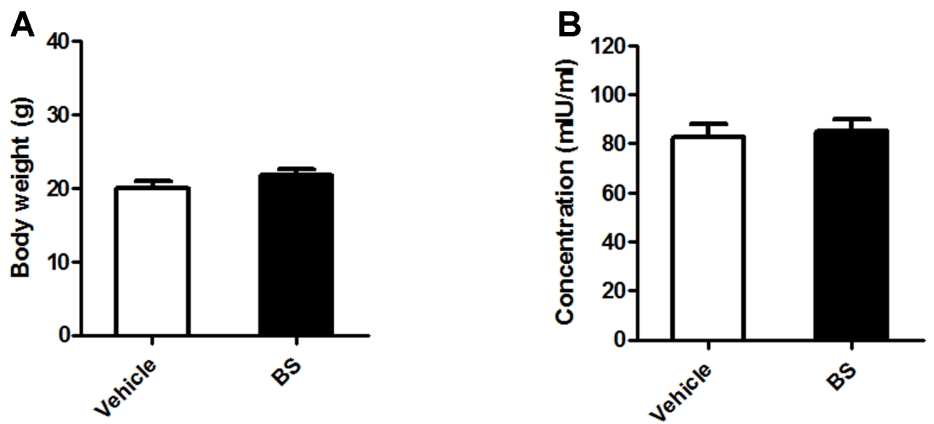

Fig. 4. Effect of BS on body weight and serum ALT concentration in BALB/c mice. Oral treatment of $B S$ or vehicle was done three days prior to infection and continued for 14 days. (A) Total body weight and (B) serum ALT concentration were determined at the end of the experiment. The data are presented as the means \pm SD of five mice in each group.
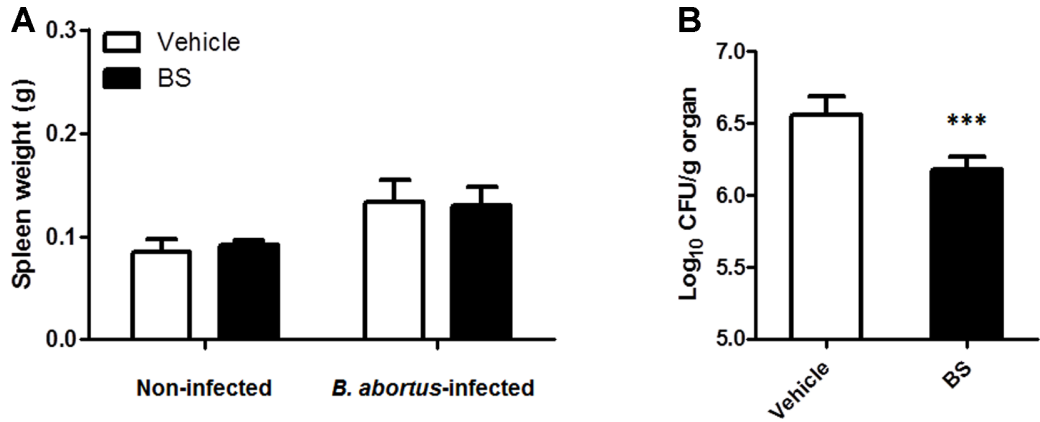

Fig. 5. Effect of BS on splenic proliferation of B. abortus in BALB/c mice. At 14 days pi, (A) spleens were collected and weighed. A part of each spleen was homogenized, diluted in PBS, and plated onto Brucella agar to determine (B) the number of CFUs. The data are presented as the mean \pm SD of five mice in each group. ${ }^{* *} P<0.001 v$ s. Brucella-infected vehicle control group.

cells [17]. In a study done by Boukes and Van de Venter [18], small but significant increases of $10-20 \%$ in phagocytosis of pHrodo Escherichia coli Bioparticles Conjugate and no significant effect on NO production were observed in human promonocytic U937 leukemia cells differentiated into monocyte-macrophages treated with BS. Although nitrite production was similar in non-infected BS-treated RAW264.7 cells, internalization of live Brucella was inhibited and nitrite production was slightly high during infection in these cells. The reduced number of surviving bacteria could be partly due to the presence of high nitrite accumulation since NO is known 
A
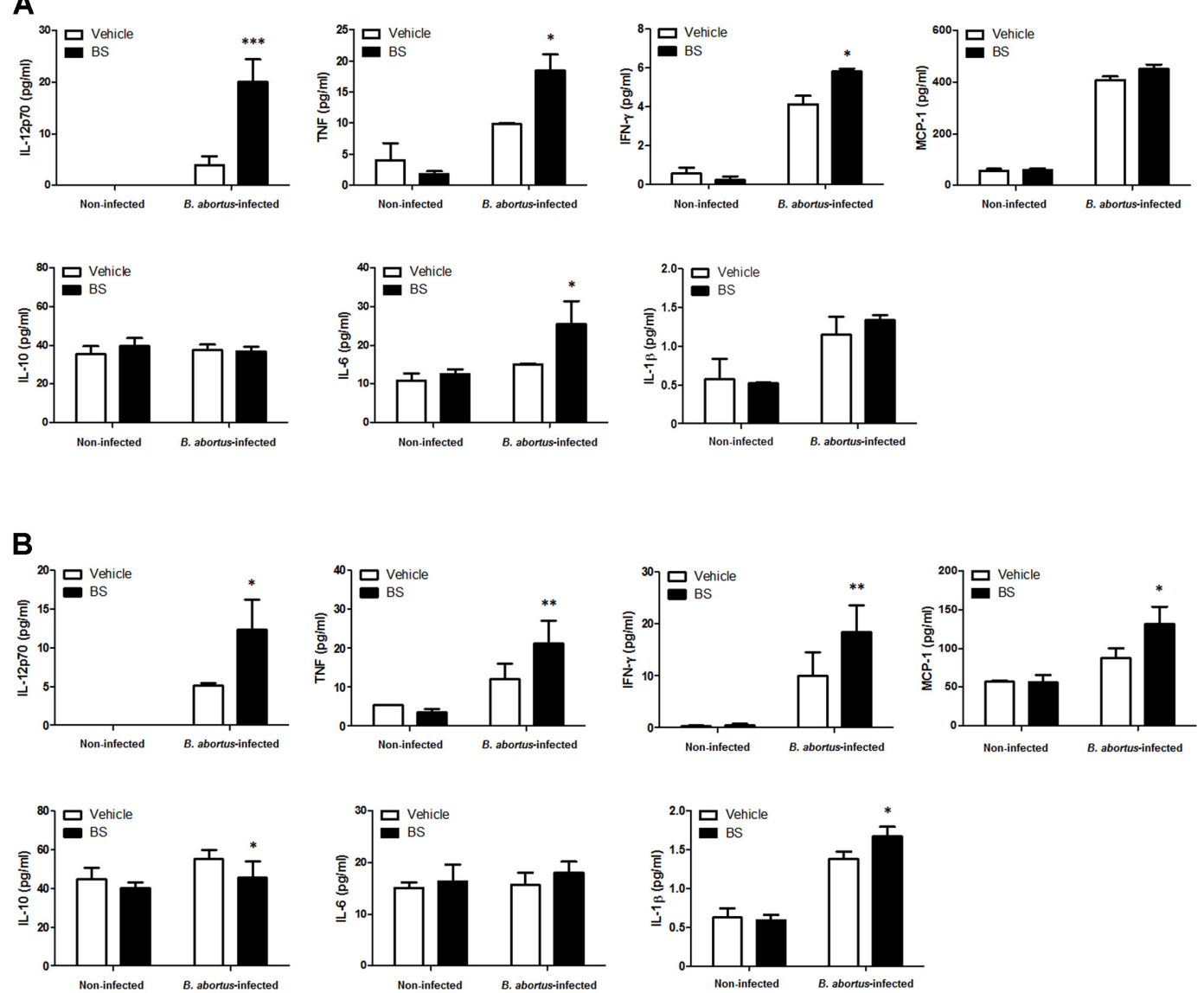

Fig. 6. Effect of BS on production of serum cytokines in BALB/c mice. Blood samples were collected at 3 and 14 days pi. Cytokines from (A) non-infected and (B) Brucella-infected groups were measured from serum samples using CBA analysis. The data are presented as the mean $\pm \mathrm{SD}$ of five mice in each group. ${ }^{*} p<0.05,{ }^{* *} p<0.01$, and ${ }^{* *} p<0.001 v$ s. control group.

as a defense mechanism that accelerates the killing of intracellular B. abortus in RAW264.7 cells during the first $24 \mathrm{~h}$ of infection [19]. Brucella has the capacity to inhibit apoptosis and extend the life of infected phagocytic cells which contributes to its pathogenicity [20]. NO has a dual nature; it could be a cytotoxic effector molecule for invading microbes, viruses and parasites as well as to host cells themselves and neighboring cells that might interact with oxygen-derived radicals to generate molecules enhancing its cytotoxicity, and a vasodilator and hence potentially protective [21]. Macrophages are capable of sustained release of high NO levels that is initiated by inflammatory cytokines and bacterial products [21], hence it is possible that BS treatment in the current study activates macrophages to produce NO in order to control Brucella infection. Previously, we reported that internalization of B. abortus was inhibited in Korean red ginseng oil-treated RAW264.7 cells with reduced bacterial adherence, F-actin content and MAPK signaling protein phosphorylation [11]. Since phytochemical analysis of Korean red ginseng oil revealed that BS was one of its most abundant compounds, BS could possibly contribute in this inhibitory mechanism exhibited by Korean red ginseng oil treatment against $B$. abortus uptake in RAW264.7 cells although further investigations are required to verify these effects. In a study done by Loizou $e t$ al. [22], BS treatment was indicated to inhibit both vascular adhesion and intracellular adhesion molecule 1 expression in TNF- $\alpha$-stimulated human aortic endothelial cells (HAECs). Fahy et al. [23] demonstrated a reduction in the uptake of beta-carotene in Caco-2 cells supplemented with BS at the same concentration used in our study. Furthermore, MAPKs are important mediators in many cellular functions including cytoskeletal rearrangement which has been a common and recurring target for obligate intracellular parasites for invasion [24]. Here BS treatment also led to downregulated MAPKs (JNK) which could interfere in the invasive mechanism of Brucella into macrophages. This is similar to suppression of phosphorylation of MAPKs (ERK, $\mathrm{JNK}$, and $\mathrm{p} 38 \alpha$ ) by BS suggesting its regulatory role in preventing the growth of renal cancer in experimental animals [25].

BS possessed bactericidal activity against different bacterial species such as Staphylococcus (S.) aureus, $S$. epidermidis, E. coli, Bacillus subtilis, and Enterococcus faecalis [10]. However, in a study done by Lampronti et al. [26], BS did not interfere with the growth of Pseudomonas (P.) aeruginosa but reduce the P. aeruginosa-dependent expression of IL-8. This compound has also been reported to effectively protect mice from lethal infection caused 
by Streptococcus pneumoniae, which was not due to direct inhibition of bacterial growth but interaction with cholesterol-dependent toxin pneumolysin [27]. In the present study, BS did not directly inhibit the growth of $B$. abortus but treatment in mice slightly reduced the proliferation of these bacteria in the spleen possibly due to promotion of proinflammatory cytokine production since another contributing factor to the pathogenicity of Brucella is the induction of poor proinflammatory responses at the early stages of infection necessary to initiate host defense against microbial invasion $[20,28]$. BS has been reported to exhibit anti-inflammatory and immunemodulating properties $[29,30]$. Here we observed that elevated cytokines during Brucella infection in BS-treated mice including IL-12, TNF, IFN- $\gamma$, and IL- $1 \beta$ are important mediators of immune responses to intracellular pathogens $[31,32,33]$, while MCP-1 also plays a central role in the maintenance of inflammation aimed to limit the infection [34]. On the other hand, reduced IL-10 production was also observed to help in the control of Brucella. IL-10 regulates the balance between the clearance of pathogen and the immune responses associated with the disease, and in a study done by Corsetti et al. [35], lack of endogenous IL-10 leads to B. abortus clearance in mice with enhanced production of proinflammatory cytokines. Furthermore, production of IL-10 is one of the causes of immunosuppression [36]. Oral treatment of BS in mice could reduce susceptibility to B. abortus infection possibly via enhanced release of proinflammatory cytokines. Furthermore, BS is structurally related to cholesterol that is slowly absorbed in the intestinal tract, hence other route of administration could be explored to maximize its beneficial effect. Overall, BS exhibited protective mechanisms against B. abortus infection via regulating invasion and intracellular survival of the pathogen, nitric oxide production and JNK phosphorylation in macrophages. On the other hand, BS slightly reduced bacterial splenic proliferation and differentially regulates cytokine production in mice. BS, as one of the most abundant compounds found in Korean red ginseng oil, could contribute to the inhibitory effects of Korean red ginseng oil against $B$. abortus infection encouraging further studies to establish practical use of BS as a supplement to feed additives, food products and medicines.

\section{Acknowledgments}

This research was supported by a fund (Project Code No.Z-1543061-2019-20-01) by Research of Animal and Plant Quarantine Agency, South Korea.

\section{Conflict of Interest}

The authors have no financial conflicts of interest to declare.

\section{References}

1. Kaden R, Ferrari S, Jinnerot T, Lindberg M, Wahab T, Lavander M. 2018. Brucella abortus: determination of survival times and evaluation of methods for detection in several matrices. BMC Infect. Dis. 18: 259.

2. Khan MZ, Zahoor M. 2018. An overview of brucellosis in cattle and humans, and its serological and molecular diagnosis in control strategies. Trop. Med. Infect. Dis. 3: 65 .

3. Barquero-Calvo E, Chaves-Olarte E, Weiss DS, Guzman-Verri C, Chacon-Diaz C, Rucavado A, et al. 2007. Brucella abortus uses a stealthy strategy to avoid activation of the innate immune system during the onset of infection. PLoS One 2: e631.

4. Meng F, Pan X, Tong W. 2018. Rifampin versus streptomycin for brucellosis treatment in humans: a meta-analysis of randomized controlled trials. PLoS One 13: e191993.

5. Aslam B, Wang W, Arshad MI, Khurshid M, Muzammil S, Rasool MH, et al. 2018. Antibiotic resistance: a rundown of a global crisis. Infect. Drug Resist. 11: 1645-1658.

6. Nath R, Das S, Sarma S, Devi M. 2014. Comparison of blood profiles between healthy and Brucella affected cattle. Vet. World. 7: 668670

7. Ali AH. 2009. The effect of brucellosis on lipid profile and oxidant-antioxidants status. Iraqi. J. Pharm. Sci. 18: 26-31.

8. Lin CJ, Lai CK, Kao MC, Wu LT, Lo UG, Lin LC, et al. 2015. Impact of cholesterol on disease progression. Biomedicine (Taipei) 5: 7.

9. Paniagua-Perez R, Madrigal-Bujaidar E, Reyes-Cadena S, Molina-Jasso D, Perez Gallaga J, Silva-Miranda A, et al. 2005. Genotoxic and cytotoxic studies of beta-sitosterol and pteropodine in mouse. J. Biomed. Biotechnol. 2005: 242-247.

10. Ododo MM, Choudhury MK, Dekebo AH. 2016. Structure elucidation of $\beta$-sitosterol with antibacterial activity from the root bark of Malva parviflora. Springerplus 5: 12210.

11. Reyes AWB, Hop HT, Arayan LT, Huy TXN, Park SJ, Kim KD, et al. 2017. The host immune enhancing agent Korean red ginseng oil successfully attenuates Brucella abortus infection in a murine model. J. Ethnopharmacol. 198: 5-14.

12. Hop HT, Reyes AWB, Huy TXN, Arayan LT, Min WG, Lee HJ, et al. 2017. Activation of NF-kB-mediated TNF-induced antimicrobial immunity is required for the efficient Brucella abortus clearance in RAW264.7 cells. Front. Cell. Infect. Microbiol. 7: 437.

13. Cargnello M, Roux PP. 2011. Activation and function of the MAPKs and their substrates, the MAPK-activated protein kinases. Microbiol. Mol. Biol. Rev. 75: 50-83.

14. Grillo MJ, Blasco JM, Gorvel JP, Moriyón I, Moreno E. 2012. What have we learned from brucellosis in the mouse model. Vet. Res. 43: 29.

15. Wang Y, Li Y, Li H, Song H, Zhai N, Lou L, et al. 2017. Brucella dysregulates monocytes and inhibits macrophage polarization through LC3-dependent autophagy. Front. Immunol. 8: 691.

16. Celli J. 2006. Surviving inside a macrophage: the many ways of Brucella. Res. Microbiol. 157: 93-98.

17. von Bargen K, Gorvel JP, Salcedo SP. 2012. Internal affairs: investigating the Brucella intracellular lifestyle. FEMS Microbiol. Rev. 36: 533-562.

18. Boukes GJ, Van de Venter M. 2016. In vitro modulation of the innate immune response and phagocytosis by three Hypoxis spp. and their phytosterol. S. Afr. J. Bot. 102: 120-126.

19. Wang M, Qureshi N, Soeurt N, Splitter G. 2001. High level of nitric oxide production decrease early but increase late survival of Brucella abortus in macrophages. Microb. Pathog. 31: 221-230.

20. Barquero-Calvo E, Mora-Cartin R, Arce-Gorvel V, de Diego JL, Chacon-Diaz C, Chaves-Olarte E, et al. Brucella induces the premature death of human neutrophils through the actin of its lipopolysaccharide. PLoS Pathog. 11: e1004853.

21. Gruenheid S, Finlay BB. 2003. Microbial pathogenesis and cytoskeletal function. Nature 422: 775-781.

22. Loizou S, Lekakis I, Chrousos GP, Moutsatsou P. 2010. $\beta$ - sitosterol exhibits anti-inflammatory activity in human aortic endothelial cells. Mol. Nutr. Food Res. 54: 551-558. 
23. Fahy DM, O'Callaghan YC, O’Brien NM. 2004. Phytosterols: lack of cytotoxicity but interference with beta-carotene uptake in Caco2 cells in culture. Food Addit. Contam. 21: 42-51.

24. Sharmila R, Sindhu G. 2017. Evaluate the antigenotoxicity and anticancer role of $\beta$-sitosterol by determining oxidative DNA damage and the expression of phosphorylated mitogen-activated protein kinases', c-fos, c-jun, and endothelial growth factor receptor. Pharmacogn. Mag. 13: 95-101.

25. Tripathi P, Tripathi P, Kashyap L, Singh V. 2007. The role of nitric oxide in inflammatory reactions. FEMS Immunol. Med. Microbiol. 51: 443-452.

26. Lampronti I, Dechecchi MC, Rimessi A, Bezzerri V, Nicolis E, Guerrini A, et al. 2017. $\beta$-sitosterol reduces the expression of chemotactic cytokine genes in cystic fibrosis bronchial epithelial cells. Front. Pharmacol. 8: 236.

27. Li H, Zhao X, Wang J, Dong Y, Meng S, Li R, et al. 2015. $\beta$-sitosterol interacts with pneumolysin to prevent Streptococcus pneumonia infection. Sci. Rep. 5: 17668.

28. Iyer SS, Cheng G. 2012. Role of interleukin 10 transcriptional regulation in inflammation and autoimmune disease. Crit. Rev. Immunol. 32: 23-63.

29. Han NR, Kim HM, Jeong HJ. 2014. The $\beta$-sitosterol attenuates atopic dermatitis-like skin lesions through down-regulation of TSLP. Expt. Biol. Med. (Maywood) 239: 454-464.

30. Kim SJ. 2017. The ameliorative effect of $\beta$-sitosterol on DNCB-induced atopic dermatitis in mice. Biomed. Sci. Lett. 23: $303-309$.

31. Zhan Y, Cheers C. 1993. Endogenous gamma interferon mediates resistance to Brucella abortus infection. Infect. Immun. 61: 48994901.

32. Macedo GC, Magnani DM, Carvalho NB, Bruna-Romero O, Gazzinelli RT, Oliveira SC. 2008. Central role of MyD88-dependent dendritic cell maturation and proinflammatory cytokine production to control Brucella abortus infection. J. Immunol. 180: 10801087.

33. Guler R, Parihar SP, Spohn G, Johansen P, Brombacher F, Bachmann MF. 2011. Blocking IL-1 $\alpha$ but not IL-1 $\beta$ increases susceptibility to chronic Mycobacterium tuberculosis infection in mice. Vaccine 29: 1339-1346.

34. Skendros P, Boura P. 2013. Immunity to brucellosis. Rev. Sci. Tech. 32: 137-147.

35. Corsetti PP, de Almeida LA, Carvalho NB, Azevedo V, Silva TMA, Teixeira HC, et al. 2013. Lack of endogenous IL-10 enhances production of proinflammatory cytokines and leads to Brucella abortus clearance in mice. PLoS One 8: e74729.

36. Picka MCM, Calvi SA, Lima CRG, Santos IAT, Marcondes-Machado J. 2005. Measurement of IL-10 serum levels in BALB/c mice treated with beta-1,3 polyglucose or sulfadiazine and acutely infected by Toxoplasma gondii. J. Venom. Anim. Toxins Incl. Trop. Dis. 11: 542 . 